\title{
Factors for high frequency plant regeneration in tissue cultures of Indian mustard (Brassica juncea L.)
}

\author{
Mohammed Shafi Ullah Bhuiyan ${ }^{1,2}$. Sung Ran Min $^{2} \cdot$ Kwan Sam Choi ${ }^{1}$. Yong Pyo Lim ${ }^{3}$. Jang Ryol Liu' ${ }^{2 *}$ \\ ${ }^{I}$ Department of Agricultural Biology, College of Agriculture and Life Sciences, Chungnam National University, Daejeon 305-764, Korea \\ ${ }^{2}$ Plant Systems Engineering Research Center, Korea Research Institute of Bioscience and Biotechnology (KRIBB), Daejeon 305-806, Korea \\ ${ }^{3}$ Department of Horticulture, Chungnam National University, Daejeon 305-764, Korea
}

\begin{abstract}
An efficient system for high frequency plant regeneration was established through investigating various factors such as plant growth regulator combinations, explant types and ages, and addition of $\mathrm{AgNO}_{3}$ influenced on shoot regeneration in Brassica juncea L. cv. BARI sarisha-10. Murashige and Skoog (MS) medium supplemented with $0.1 \mathrm{mg} / \mathrm{L}$ NAA (1-naphthaleneacetic acid) and $1 \mathrm{mg} / \mathrm{L} \mathrm{BA}$ (6-benzyladenine) showed the maximum shoot regeneration frequency (56.67\%) among the different combinations of NAA and BA. Explant type, explant age, and addition of $\mathrm{AgNO}_{3}$ also significantly affected shoot regeneration. Of the four type of explants (cotyledon, hypocotyl, root, and leaf explants)- cotyledon explants produced the highest shoot regeneration frequency and hypocotyls explants produced the highest number of shoots per explant, whereas root explants did not produce any shoot. The cotyledonary explants from Four-day-old seedlings showed the maximum shoot regeneration frequency and number of shoots per explant. Shoot regeneration frequency increased significantly by adding $\mathrm{AgNO}_{3}$ to the medium. Two $\mathrm{mg} / \mathrm{L} \mathrm{AgNO} 3$ appeared to be the best for shoot regeneration with the highest shoot regeneration frequency (86.67\%) and number of shoots per explant (7.5 shoots). Considerable variation in shoot regeneration from cotyledonay explants was observed within the $B$. juncea L. genotypes. The shoot regeneration frequency ranged from $47.78 \%$ for cv. Shambol to $91.11 \%$ for cv. Rai- 5 . In terms of the number of shoots produced per explant, B. juncea L. cv. Daulot showed the maximum efficiency. MS medium supplemented with $0.1 \mathrm{mg} / \mathrm{L}$ NAA showed the highest frequency of rooting. The regenerated plantlets were transferred to pot soil and grown to maturity in the greenhouse. All plants were fertile and morphologically identical with the source plants.
\end{abstract}

\section{Introduction}

Brassica crops are the third most important source of vegetable oil after soybean and oil palm worldwide. Indian mustard (Brassicajuncea L.) has become a better choice as oilseed crop over other Brassica species due to its increased heat, drought, and disease tolerance (Burton et al. 2003; Pandian et al. 2006). Recently, it has also been considered as suitable plant species for phytoremediation projects, as it is rapid and fast growing in nature, able to produce high biomass and accumulate heavy metals from the soils (Raskin et al. 1997; Clemente et al. 2005).

An efficient tissue culture system is thought to be crucial to the success of plant genetic engineering, since the efficiency of Agrobacterium-mediated transformation is considered to be dependent on two

*Corresponding author Tel 042-860-4430 Fax 042-860-4608 E-mail: jrliu@kribb.re.kr primary factors: 1) the Agrobacterium infection efficiency, and 2) the regeneration frequency from the infected tissues (Takasaki et al. 1997). B. juncea is considered to be amenable to tissue culture and transformation techniques. A variety of plant tissues have been used for shoot regeneration of B. juncea, including cotyledons (Hachey et al. 1991; Guo et al. 2005), hypocotyls and petiole (Pua and Chi; 1993), leaf discs (Eapen and George; 1996), peduncle (Eapen and George; 1997), thansverse thin cell layers (Bhuiyan et al. 2009), microspores (Lionneton et al. 2001; Prem et al. 2005), and protoplasts (Xu et al. 1982; Chatterjee et al. 1985). Most of these studies had been focused on determining the requirements of various plant growth regulators, mineral nutrients and explant types for different organogenic process. However, a systematic and comprehensive study based on various factors influencing plant regeneration has seldom been conducted.

In this communication, we report a high efficient plant regeneration 
system in $B$. juncea $\mathrm{L}$. by optimizing several factors including combinations of plant growth regulators (PGRs), explant types and ages, and addition of $\mathrm{AgNO}_{3}$ (ethylene inhibitor) to the medium that can significantly affect the efficiency of adventitious shoot formation. Special attention was also given to Brassica genotypes to determine its influence on shoot regeneration.

\section{Materials and methods}

Plant material

Five Brassica juncea L. cultivars (BARI sarisha-10, BARI sarisha11, Daulot, Rai-5, and Shambol) were used to evaluate shoot regeneration. These five cultivars are pure lines, genetically fixed, and were obtained by self-pollination.

\section{Explant preparation}

Seeds were surface-sterilized by immersion for $30 \mathrm{~s}$ in $70 \%$ ethanol (v/v), 10 min in 10\% Chlorox (v/v), followed by three 3-min rinses in sterilized distilled water. The seeds were then germinated in Petri dishes $(100 \times 40 \mathrm{~mm})$ on MS basal solid medium containing Murashige and Skoog (1962) salts and vitamins (Duchefa Biochemie B.V., Haarlem,

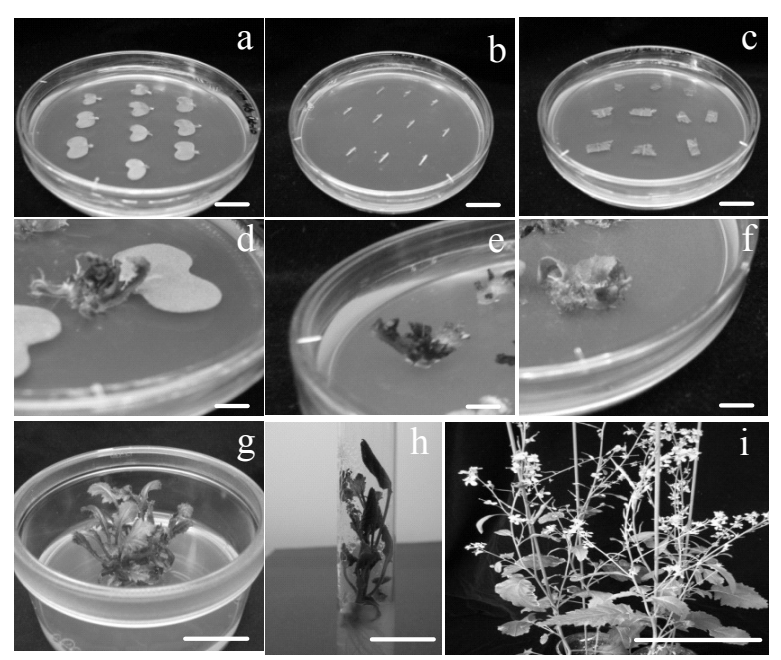

Figure 1. The regeneration process in $B$. juncea L. cv. BARI sarisha- 10 . (a) cotyledon explants, (b) hypocotyl explants, (c) leaf segment explants, (d, e, and f) shoot regeneration in MS medium supplemented with 0.1 $\mathrm{mg} / \mathrm{L} \mathrm{NAA}, 1 \mathrm{mg} / \mathrm{L} \mathrm{BA}$ and $2.0 \mathrm{mg} / \mathrm{L} \mathrm{AgNO}_{3}$ from cotyledon, hypocotyl and leaf segment explants, respectively, (g) shoot elongation on MS medium supplemented with $0.1 \mathrm{mg} / \mathrm{L} \mathrm{BA}$, (h) root induction of regenerated shoot, (i) flowering of regenerated plants. Scale bars represent $5 \mathrm{~mm}(\mathrm{a}, \mathrm{b}, \mathrm{c}, \mathrm{d}, \mathrm{e}, \mathrm{f}), 1 \mathrm{~cm}(\mathrm{~g}, \mathrm{~h})$, and $10 \mathrm{~cm}$ (i) the Netherlands) and $3 \%(\mathrm{w} / \mathrm{v})$ sucrose and incubated at $25^{\circ} \mathrm{C}$ under a 16-h photoperiod with $40 \mu \mathrm{mol} . \mathrm{m}^{-2} . \mathrm{s}^{-1}$ light provided by cool white fluorescent lamps. Cotyledons including 1-2 mm petioles and hypocotyls were excised from 4-day old seedlings (Fig. 1a \& b). The cotyledons were carefully excised from the hypocotyls and apical shoot meristems. The hypocotyls portion that contacted with the medium and root tip of seedlings were discarded. The hypocotyls and roots were cut into 4-5 $\mathrm{mm}$ length segments. For leaf explants, seedlings allowed to grow for 15 days on MS basal medium to develop the true leaves. Approximately $5 \times 5 \mathrm{~mm}^{2}$ leaf segments (Fig. 1c) were excised using a sterile scalpel and forceps.

\section{Culture medium}

To select the optimum medium for shoot regeneration, cotyledonary explants were cultured on MS medium including vitamins supplemented with different combinations of BA $(0.5-4 \mathrm{mg} / \mathrm{L})$ and NAA $(0$ $-0.4 \mathrm{mg} / \mathrm{L}$ ) and $30 \mathrm{~g} / \mathrm{L}$ sucrose . Different concentration of $\mathrm{AgNO}_{3}$ (filter sterilized by $0.2 \mu \mathrm{m}$ filter) were added to the medium to investigate the effects on shoot regeneration. All media were solidified with agar $(8$ $\mathrm{g} / \mathrm{L}$ ), adjusted to $\mathrm{pH} 5.7$ by $0.1 \mathrm{~N} \mathrm{NaOH}$ and autoclaved at $121^{\circ} \mathrm{C}$ and $1 \mathrm{~kg} \mathrm{~cm}^{-2}$ for $15 \mathrm{~min}$.

\section{Culture method}

Hypocotyl and root segments were placed horizontally into the surface of the medium, whereas excised cotyledons with petiole were placed upright with petiole in contact with the medium. Leaf segments were placed abaxial side downward onto medium. Ten to 15 explants were cultured in each Petri dish $(90 \times 15 \mathrm{~mm})$. The culture plates were sealed with Parafilm and were incubated in the same conditions as previously described. Shoot regeneration studies were performed with 30 explants per set in three replicates for each treatment. The number of explants with shoot buds was scored after 2 weeks culture and the number of shoots formed per explant was counted as well. Regenerated shoot buds were sub-cultured on MS medium supplemented with 0.1 $\mathrm{mg} / \mathrm{L} \mathrm{BA}$ in Petri dish $(100 \times 40 \mathrm{~mm})$ for shoot elongation. About 2-3 $\mathrm{cm}$ long shoots were cut and transferred to MS medium supplemented with different concentration of NAA (0-0.4 mg/L) for rooting.

Hardening and transplantation 


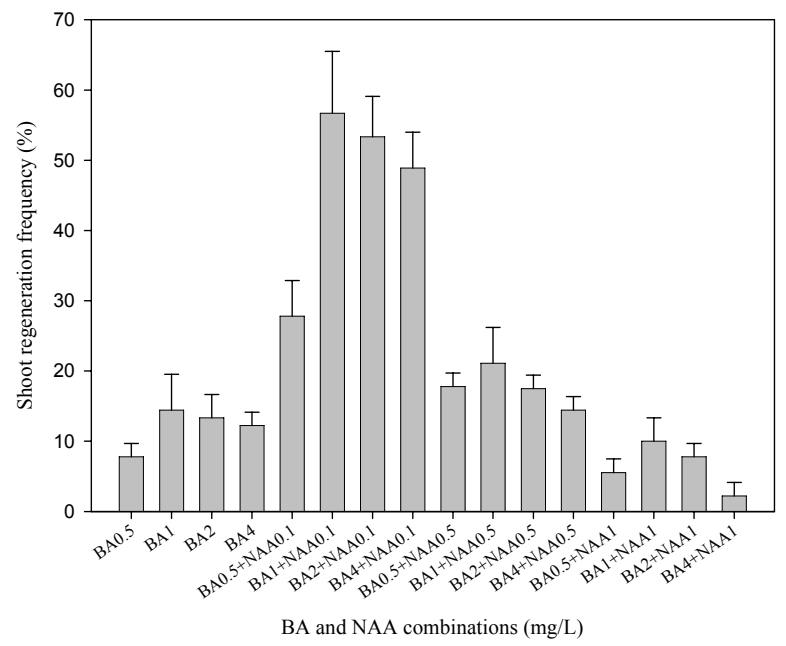

Figure 2. Frequency of shoot regeneration from 4-d-old cotyledon explants of $B$. juncea L. cv. BARI sarisha- 10 on MS medium containing various combinations of BA and NAA. Data consist of three replicates and 30 explants were used for each replicate. Bars represent standard deviation (SD) of the means

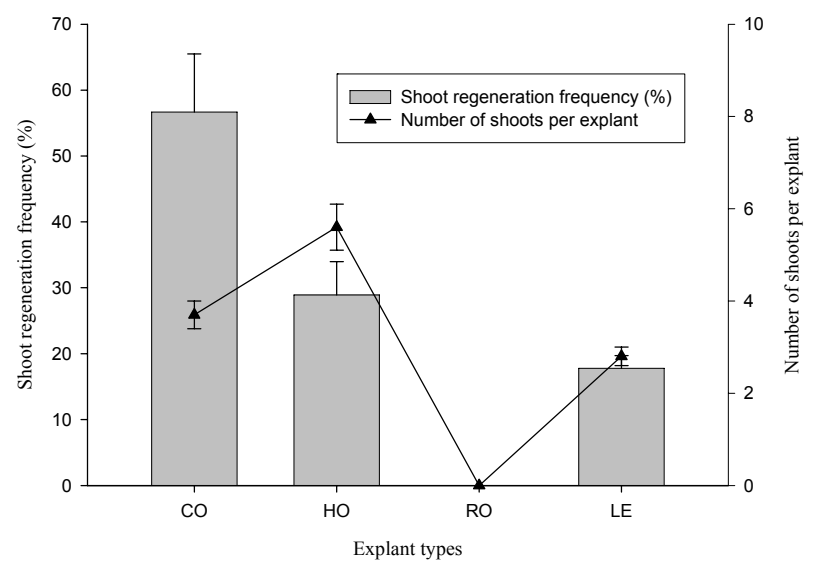

Figure 3. Effect of explant types on shoot regeneration in $B$. juncea L. cv. BARI sarisha-10. CO, HO, RO and LE indicate cotyledon, hypocotyl, root, and leaf segment explants, respectively. Bars represent SD of the means

The rooted plantlets were thoroughly washed in tap water and transferred to moistened soil in pot. The plants were covered with polythene bags for maintaining the humidity and acclimatized under a $16 \mathrm{~h} \mathrm{pho-}$ toperiod with $40 \mu \mathrm{mol} . \mathrm{m}^{-2} . \mathrm{s}^{-1}$ light for 5 days. Then acclimatized plants were transferred to the naturally-lighted greenhouse.

\section{Statistical analysis}

The number of explants that produced adventitious shoots and the number of shoots per explant were counted and the frequency of shoot formation was calculated. There were 30 explants for shoot regeneration and 10 explants for in vitro rooting per treatment. Each experiment was repeated 3 times. All statistical analyses were done using SAS version 9.1 (SAS Institute, Carey NC, USA) and the differences among means ( $5 \%$ level of significance) were tested by using a Dunkan Multiple Range Test (DMRT). All graphs were performed using Sigma Plot version 10 (Systat Software Inc., CA, USA).

\section{Results}

The optimal medium for shoot regeneration

The optimum medium for shoot regeneration from cotyledonary explants in $B$. juncea L. cv. BARI sarisha-10 was determined using various combinations of BA and NAA (Fig. 2). Typically, the explants had swollen after 3-4 days of culture and shoot buds appeared within a week. Explants cultured on hormone-free basal medium (control) did not produce any shoot, and died after a few days. Shoot regeneration was markedly enhanced by the addition of NAA to BA. From a total of 16 combinations of BA and NAA tested, the highest shoot regeneration frequency (56.67\%) was obtained in MS medium supplemented with $0.1 \mathrm{mg} / \mathrm{L} \mathrm{NAA}$ and $1 \mathrm{mg} / \mathrm{L}$ BA. This medium was termed as shoot regeneration medium (SRM). Higher concentrations of NAA $(>0.1 \mathrm{mg} / \mathrm{L})$ in combination with BA resulted in profound callus formation and occasionally in hairy root development. In SRM, shoot buds were produced directly on the cut ends of cotyledon (Fig. 1d) within 7 days. No callus was observed in cotyledon explants during the first $10 \mathrm{~d}$ of culture. Profound callus with multiple shoot buds was found in hypocotyls explants (Fig. 1e). Shoot bud production proceeded directly from the cotyledon explants, without an intervening callus phase. However, small calluses were formed at the cut-ends of the cotyledon explants after 2 weeks in culture, and roots appeared on the callus that was not in direct contact with the culture medium.

Influence of explant types

In this work, we used 4 -different types of explants such as cotyledons (CO), hypocotyls (HY), root segments (RO), and leaf segments (LE). The highest shoot regeneration frequency (56.67\%) was achieved using cotyledon explants cultured on SRM (MS medium supplemented with $0.1 \mathrm{mg} / \mathrm{L} \mathrm{NAA}$ and $1 \mathrm{mg} / \mathrm{L} \mathrm{BA}$ ) whereas hypocotyls explants produced highest number of shoots (5.6) per explant on the same me- 


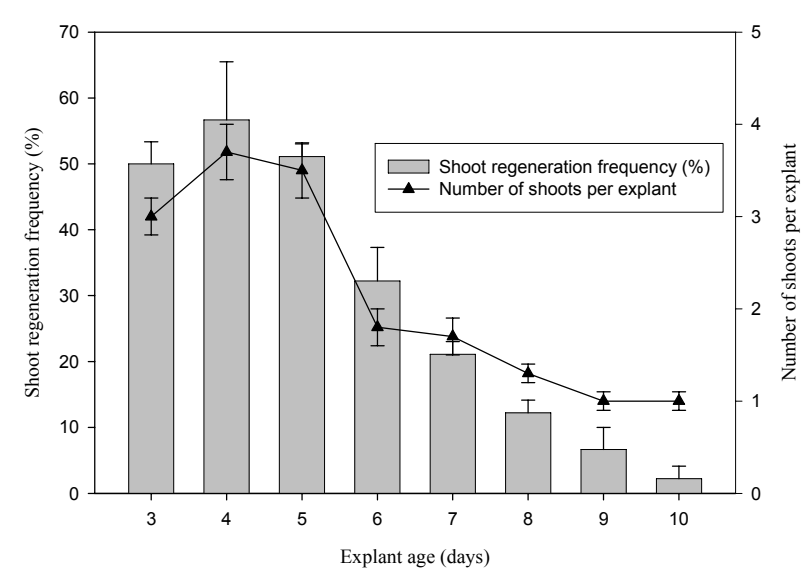

Figure 4. Effect of explant age on shoot regeneration from cotyledon explants in B. juncea L. cv. BARI sarisha-10. Data consist of three replicates and 30 explants were used for each replicate. Bars represent SD of the means

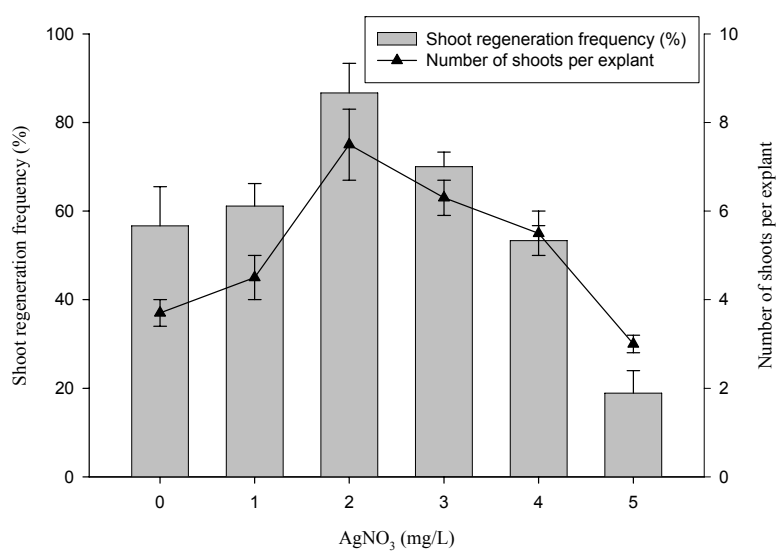

Figure 5. Effect of $\mathrm{AgNO}_{3}$ concentration on shoot regeneration from cotyledon explants in $B$. juncea L. cv. BARI sarisha-10. Data consist of three replicates and 30 explants were used for each replicate. Bars represent SD of the means

dium (Fig. 3). Root segment explants were least responsive and had no shoot induction, only produced calluses. This callus was semi-friable and did not regenerate plants on subculture despite several attempts.

We also studied the in vitro response of cotyledons and hypocotyls further by isolating the 2 cotyledons (large cotyledon and small cotyledon) of seedling and hypocotyls sections (upper hypocotyls and lower hypocotyls section). There was no significant difference in the regeneration capacity between the two cotyledons and hypocotyls sections (data not shown).

Influence of explant age

The results indicate that the frequency of shoot regeneration was affected by the age of the explant source material (seedling) (Fig. 4).
Explants from younger seedlings ( $\leq 2$ days) were too small, and withered very quickly. Cotyledons from 4-d-old seedlings were the most regenerative, with a maximum of $56.67 \%$ of the explants regenerating shoots after 14 days of culture. The shoot regeneration frequency decreased with the increase in explant age from 4 to 10 days. However, the shoot regeneration frequency of explants from 3 to 5-d-old seedlings showed no obvious difference, but a steady decrease in shoot regeneration frequency was apparent from the explants derived from seedlings 6-10 days old. This suggests that explants of 3-5 days post-germination are more suitable for adventitious shoot formation. This observation is in agreement with previous work on B. napus (Tang et al. 2003). The average number of shoots produced per explant was also varied significantly with the explant age.

Influence of $\mathrm{AgNO}_{3}$

The frequency of shoot regeneration and number of shoots per explant were markedly enhanced by ethylene biosynthesis inhibitor $\mathrm{AgNO}_{3}$ (Fig. 5). The level of enhancement of shoot regeneration depended on the concentration of $\mathrm{AgNO}_{3}$. The highest regeneration rate (86.67\%) and highest number of shoots per explant were observed when cotyledons from 4-d-old seedlings were cultured on SRM with $2 \mathrm{mg} / \mathrm{L}$ $\mathrm{AgNO}_{3}$. Shoot number was about threefold more than that obtained on the medium without $\mathrm{AgNO}_{3}$. Shoot regeneration was dramatically inhibited by high concentrations of $\mathrm{AgNO}_{3}(\geq 2 \mathrm{mg} / \mathrm{L})$.

\section{Genotypic variation}

SRM (MS medium added with $1.0 \mathrm{mg} / \mathrm{L}$ BA and $0.1 \mathrm{mg} / \mathrm{L} \mathrm{NAA}$ ) supplemented with $2 \mathrm{mg} / \mathrm{L} \mathrm{AgNO}_{3}$ ) were used to investigate the shoot regeneration ability of five genotypes of $B$. juncea $\mathrm{L}$. The shoot regeneration ability is strongly influenced by the genotypes. The frequency of shoot formation ranged from $47.78 \%$ in Shambol to $91.11 \%$ in Rai-5 (Fig. 6). The number of shoots per explant ranged from 3.5 in Shambol to 8.2 in Rai-5 (Fig. 6). DMRT shows that frequency of shoot regeneration and the number of shoots per explant is significantly affected by genotype $(\mathrm{P} \leq 0.05)$.

\section{In vitro rooting of regenerated shoots and acclimatization}

The regenerated shoots were subjected to root induction in MS medium supplemented with different concentrations of NAA. About 


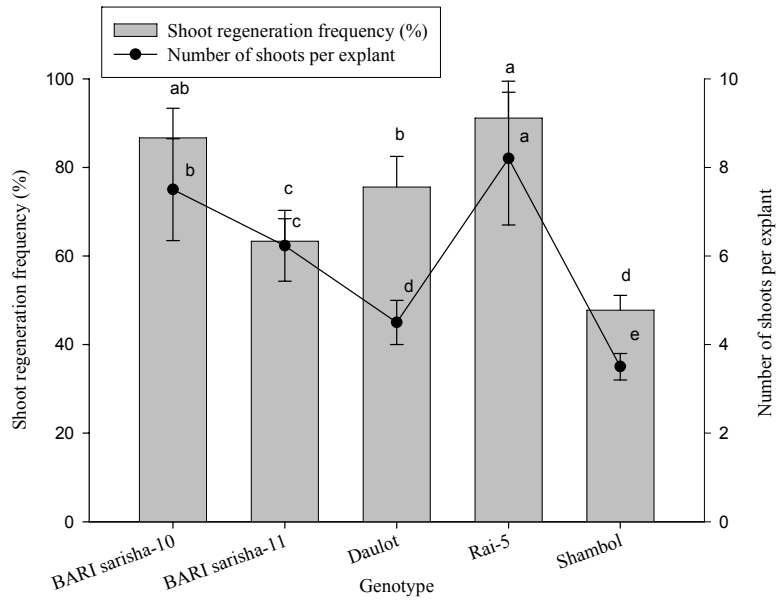

Figure 6. Influence of genotype on shoot regeneration from cotyledon explants in B. juncea L. Data consist of three replicates and 30 explants were used for each replicate. Bars represent SD of the means. Values with different letters are significantly different at $\mathrm{P} \leq 0.05$ (DMRT)

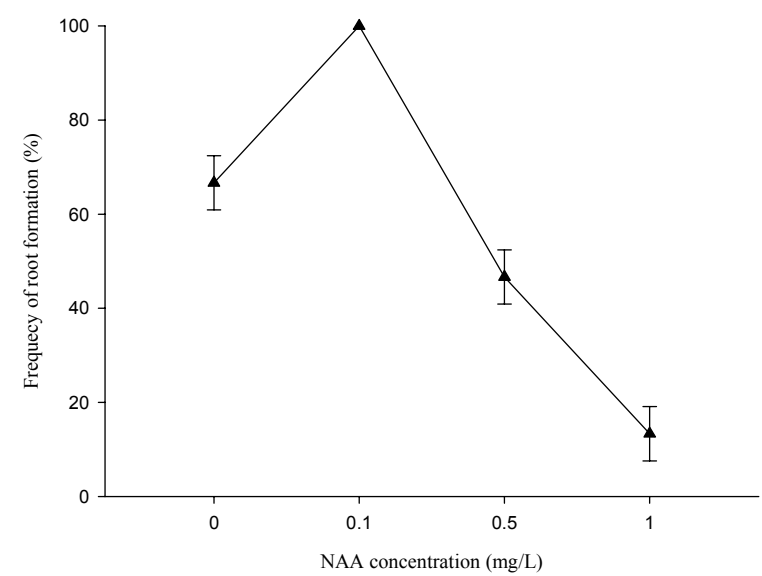

Figure 7. Influence of different NAA concentrations on rooting of regenerated shoots from cotyledon explants of B. juncea L. cv. BARI sarisha-10. Data consist of three replicates and 10 explants were used for each replicate. Bars represent SD of the means

2-3 cm long distinct shoots were excised and transferred to rooting medium in culture tubes. Roots started to emerge within 4-days. The highest frequency of root induction (100\%) was observed in MS medium supplemented with $0.1 \mathrm{mg} / \mathrm{L}$ NAA (Fig. 7). Plantlets produced well developed root systems within 12 days in rooting medium (Fig. 1h), and plantlets were transferred to pot soil. The plants were covered by plastic bags with holes for 5-days to maintain humidity. After that the plants were transferred to the greenhouse and irrigated every alternate day with normal tape water. The success rate of this transfer was $90 \%$. After 25-28 days, the plants produced flowers and no difference was observed in the morphology of these regenerated plants compared with seed-derived control plants.

\section{Discussion}

The procedure described here is the successful plant regeneration system for Brassica juncea L. through direct organogenesis (Fig. 1) using a range of explants. In our experiments, all the factors evaluated (plant growth regulators, explant types and ages, $\mathrm{AgNO}_{3}$, and genotype) influenced shoot regeneration. It was demonstrated that regeneration efficiency depends on medium components such as minerals, nutrients, sugar, vitamins and plant growth regulators (PGRs). To determine the optimal concentrations of PGRs in the medium, various combinations NAA $(0,0.1,0.5$, and $1.0 \mathrm{mg} / \mathrm{L})$ and BA $(0.5,1,2$, and $4 \mathrm{mg} / \mathrm{L})$ on MS medium were studied. All concentrations of BA combined with NAA offered better results compared to the use of $B A$ alone. High concentration of $\mathrm{BA}(\leq 4 \mathrm{mg} / \mathrm{L})$ was excessive and produced vitrification and death of shoots. In the absence of PGRs, no shoot regeneration was observed, suggesting that the presence of PGRs is the critical factor for shoot regeneration of $B$. juncea $\mathrm{L}$. This agrees with results reported by Bhuiyan et al. (2009), who stated that BA and NAA were indispensable for shoot regeneration from transverse thin cell layers (tTCLs) of $B$. juncea $\mathrm{L}$.

The shoot organogenesis requires plant cells to undergo dedifferentiation and redifferentiation. These two processes are determined not only by exogenous PGRs in the medium, but also endogenous plant hormone levels (Trigiano and Gray 2000). Different tissues have different levels of endogenous plant hormones, thus the source of explants has a critical impact on plant tissue culture. Previous studies showed that cotyledon (Yang et al. 2004), hypocotyls (Pua and Chi 1993), root sections (Bhalla and Smith 1998), and leaf segments (Guo et al. 2005) were the most responsive explants for in vitro regeneration of Brassica species. In our study, cotyledons, hypocotyls, root and leaf segments were used as explants to determine the suitable explant type for regeneration of $B$. juncea $\mathrm{L}$. All explants showed the development of shoots except root. Shoot regeneration frequency and the number of shoots per explant varied with the explant types (Fig. 3). Cotyledonary explants exhibited the highest shoot regeneration frequency while hypocotyl explants developed the highest number of shoots per explant followed by cotyledons and leaf segments. This result compares favorably with recent studies of shoot regeneration of B. rapa ssp. Pekinensis (Yang et al. 2004). The root segment explants did not form shoots indicates that a significant interspecific difference 
in shoot regeneration exists among the Brassica species. The use of cotyledonary explants for in vitro plant regeneration has several advantages. A large number of cotyledonary explants can be obtained by germinating seeds under sterile conditions over a short period of time all year round. Micro-organism contamination of such explants can be manipulated and has seldom been a serious problem. Moreover, cotyledonary explants possess high morphogenic potential.

Cotyledonary explants derived from 4-d-old seedlings showed the highest frequency of shoot regeneration. The cotyledons derived from 6-d-old and older seedlings exhibited yellowing of the lamina after 10-12 days of culture. The effect of explant age on shoot regeneration potential is in agreement with the responses of $B$. juncea (Sharma et al. 1990), B. rapa (Yang et al. 2004), and B. napus (Tang et al. 2003). It has already been established that younger explants exhibit greater morphogenic potential than older explants (Yepes and Aldwinckle 1994), as they might have more metabolically active cells with hormonal and nutritional conditions that are responsible for increased organogenesis (Famiani et al. 1994).

The addition of $\mathrm{AgNO}_{3}$ was significantly beneficial to shoot regeneration for $B$. juncea L. cv. BARI sarisha-10. The positive effect of $\mathrm{AgNO}_{3}$ was consistent with previous results from the traditional explants such as cotyledons of Brassica rapa ssp. oleifera (Burnett et al. 1994), Brassica campestris ssp. pekinensis (Chi et al. 1991; Zhang et al. 1998), hypocotyls of Brassica juncea (Pua and Chi 1993) and Raphanus sativus (Pua et al. 1996), peduncle and leaf segments of Brassica napus (Eapen and George 1997; Akasaka-Kennedy et al. 2005). $\mathrm{AgNO}_{3}$ is a potent inhibitor of ethylene action, and ethylene is considered to suppress shoot morphogenesis in vitro. Zhang et al. (1998) showed that $\mathrm{AgNO}_{3}$ enhanced both shoot regeneration frequency and ethylene production in $B$. campestris. The increase of ethylene production by $\mathrm{AgNO}_{3}$ is considered to be due to interference from ethylene perception or stress induced by $\mathrm{Ag}^{+}$. They considered that the increase of shoot regeneration frequency by $\mathrm{AgNO}_{3}$ is caused by the interruption of an ethylene signal transduction pathway. Shoot regeneration frequency and number of shoots per explant were enhanced by increasing $\mathrm{AgNO}_{3}$ concentration. But the presence of excess $\mathrm{AgNO}_{3}$, especially more than $2 \mathrm{mg} / \mathrm{L}$ seems to be sensitive significantly in the enhancement of shoot regeneration and the number of shoots per explants as well.

Shoot regeneration in $B$. juncea $\mathrm{L}$. is highly variable and genotype specific. Genotypic influence on in vitro morphogenesis has been documented previously on in B. juncea (Chi et al. 1990), B. napus, B. campestris and R. sativus L. (Ono et al. 1994; Takasaki et al. 1996; Zhang et al. 1998; Murakami et al. 1995). In our study, shoot regeneration ability also influenced by genotype in $B$. juncea L. Such genotypic variability indicates the genetic control of shoot regeneration ability.

Regenerated shoots developed from different explants were too small and they were transferred to MS medium supplemented with $0.1 \mathrm{mg} / \mathrm{L}$ BA for shoot elongation. 2-3 cm elongated shoots were cut and transferred to MS medium containing different concentration of NAA for rooting. The frequency of rooting was the highest (100\%) in the MS medium supplemented with $0.1 \mathrm{mg} / \mathrm{L}$ NAA. Increasing concentration of NAA dramatically decreased the frequency of rooting. Plantlets with well developed roots were acclimatized and successfully transplanted to the greenhouse.

In conclusion, we developed an efficient regeneration system of $B$. juncea L. Cotyledon explants from 4-day-old seedlings was the best explant source for shoot regeneration and was able to induce in MS medium supplemented with $1 \mathrm{mg} / \mathrm{l} \mathrm{BA}, 0.1 \mathrm{mg} / \mathrm{l} \mathrm{NAA}$ and $2 \mathrm{mg} / \mathrm{l}$ $\mathrm{AgNO}_{3}$. Regenerated shoots were rooted at $100 \%$ in MS medium supplemented with $0.1 \mathrm{mg} / \mathrm{L}$ NAA. This procedure developed in this study can be used in Agrobacterium-mediated transformation of $B$. juncea $\mathrm{L}$.

\section{Acknowledgements}

This work was supported by a grant to KSC from the Korea Research Foundation funded by the Korean Ministry of Education, Science and Technology (MOEHRD) (KRF-2007-211) and a grant to YPL from the Technology Development Program for Agriculture and Forestry funded by the Korean Ministry of Food, Agriculture, Forestry and Fisheries (Grant No. 607003-05). The authors are grateful to Mr. M. A.N. Nazim-ud-Dowla (Bangladesh Agricultural Research Institute, Gazipur, Bangladesh) for providing all Brassica juncea L. seeds.

\section{References}

Akasada-Kennedy Y, Yoshida H, Takahata Y (2005) Efficient plant regeneration from leaves of rapeseed (Brassica napus L.): The influence of $\mathrm{AgNO}_{3}$ and genotype. Plant Cell Rep 24: 649-654

Bhalla PL, Smith NA (1998) Comparison of shoot regeneration potential from seedling explants of Australian cauliflower (Brassica oleracea var. botrytis) varieties. Aust J Agric Res 49:1261-1266 
Bhuiyan MSU, Lim YP, Min SR, Choi KS, Liu JR (2009) High frequency plant regeneration from transverse thin cell layers in Indian mustard (Brassica juncea L.). J Plant Biotechnol 36: 81-86

Burnett L, Arnoldo M, Yarrow S, Huang B (1994) Enhancement of shoot regeneration from cotyledon explants of Brassica rapa ssp. oleifera through pretreatment with auxin and cytokinin and use of ethylene inhibitors. Plant Cell Tiss Org Cult 35: 253-258

Burton WA, Salisbury P, Potts D (2003) The potential of canola quality Brassica juncea as an oilseed crop for Australia. In: Proceedings of the $13^{\text {th }}$ biennial Australian research assembly on Brassicas. Tamworth, NSW, Australia, pp 62-64

Chatterjee G, Sikdar SR, Das S, Sen SK (1985) Regeneration of plantlets from mesophyll protoplasts of Brassica juncea (L.) Czern. Plant Cell Rep 4:245-247

Chi GL, Barfield DG, Sim GE, Pua EC (1990) Effect of silver nitrate and aminoethoxyvinylglycine on in vitro shoot and root organogenesis from seedling explants of recalcitrant Brassica genotypes. Plant Cell Rep 9:195-198

Chi GL, Pua EC, Goh, CJ (1991) Role of ethylene on de novo shoot regeneration cotyledonary explants of Brassica campestris pekinensis (Lour) Olsson in vitro. Plant Physiol 96:178-183

Clemente R, Walker DJ, Bernal MP (2005) Uptake of heavy metals and As by Brassica juncea grown on contaminated soil in Aznalcollar (Spain): the effects of soil amendments. Environ Pollut 138:46-58

Eapen S, George L (1996) Enhancement in shoot regeneration from leaf discs of Brassica juncea L. Czern. and Coss. by silver nitrate and silver thiosulfate. Physiol Mol Biol Plants 2:83-86

Eapen S, George L (1997) Plant regeneration from peduncle segments of oil seed Brassica species: Influence of silver nitrate and silver thiosulfate. Plant Cell Tiss Org Cult 51:229-232

Famiani F, Ferradini N, Staffolani P, Standari A (1994) Effect of leaf excision time and age, BA concentration and dark treatments on in vitro shoot regeneration of M.26 apple rootstock. J Hortic Sci 69:679-685

Guo DP, Zhu ZJ, Hu XX, Zheng SJ (2005) Effects of cytokinins on shoot regeneration from cotyledon and leaf segment of stem mustard Brassica juncea var. Tsatsai. Plant Cell Tiss Org Cult 83:123-127

Hachey JE, Sharma KK, Moloney MM (1991) Efficient shoot regeneration of Brassica campestris using cotyledon explants cultured in vitro. Plant Cell Rep 9:549-554

Lionneton E, Beuret W, Delaitre C, Ochatt S, Rancillac M (2001) Improved microspore culture and doubled-haploid plant regeneration in the brown condiment mustard (Brassica juncea). Plant Cell Rep 20:126-130

Murakami T, Ono Y, Takahata Y (1995) Phytohormonal and genotypic factors affecting shoot regeneration from cotyledonary explant of raddish (Raphanus sativus L.) Plant Cell Tiss Organ Cult Lett 12:321-323
Murashige T, Skoog F (1962) A revised medium for rapid growth and bioassay with tobacco tissue culture. Physiol Plant 15:473-497

Ono Y, Takahata Y, Kaizuma N (1994) Effect of genotype on shoot regeneration from cotyledonary explants of rapeseed (Brassica napus L.). Plant Cell Rep 14:13-17

Pandian A, Hurlstone C, Liu Q, Singh S, Salisbury P, Green A (2006) Agrobacterium-mediated transformation protocol to overcome necrosis in elite Australian Brassica juncea lines. Plant Mol Biol Rep 24:103a-103i

Prem D, Gupta K, Agnihotri A (2005) Effect of various exogenous and endogenous factors on microspore embryogenesis in Indian mustard [Brassica juncea (L.) Czern. and Coss.]. In Vitro Cell Dev Biol Plant 41:266-273

Pua EC, Chi GL (1993) De novo shoot morphogenesis and plant growth of mustard (Brassica juncea) in vitro in relation to ethylene. Physiol Plant 88:467-474

Pua EC, Sim GE, Chi GL, Kong LF (1996) Synergistic effect of ethylene inhibitors and putrescine on shoot regeneration from hypocotyls explants of Chinese raddish (Raphanus sativus L. var longipinnatus Bailey) in vitro. Plant Cell Rep 15:685-690

Raskin I, Smith RD, Salt DE (1997) Phytoremediation of metals: using plants to remove pollutants from the environment. Curr Opin Biotechnol 8:221-226

Sharma KK, Bhojwani SS, Thorpe TA (1990) Factors affecting high frequency differentiation of shoots and roots from cotyledon explants of Brassica juncea (L.) Czern. Plant. Sci. 66: 247-253

Takasaki T, Hatakayama K, Ojima K, Watanbe M, Toriyama K, Hinata K (1997) Factors influencing Agrobacterium-mediated transformation of Brassica rapa L. Breed Sci 47:127-134

Tang GX, Zhou WJ, Li HZ, Mao BZ, He, ZH, Yoneyama, K (2003) Medium, explant and genotype factors influencing shoot regeneration in oilseed Brassica spp. J Agron Crop Sci 189:351-358

Trinigiano RN, Gray DJ (eds) (2000) Plant tissue culture concepts and laboratory exercises, $2^{\text {nd }}$ ed. CRC Press, Boca Raton, London, New York, Washington, DC

Xu Z, Davey MR, Cocking EC (1982) Plant regeneration from root protoplasts of Brassica. Plant Sci Lett 24:117-121

Yang ZH, Jin H, Plaha P, Woong BT, Jiang GB, Woo JG, Yun HD, Lim YP, Lee HY (2004) An improved plant regeneration protocol using cotyledonary explants from inbred lines of Chinese cabbage (Brassica rapa spp. Pekinensis). J Plant Biotecnol 6:235-239

Yepes LM, Aldwinckle HS (1994) Factors that affect leaf regeneration efficiency in apple, and effect of antibiotics in morphogenesis. Plant Cell Tissue Organ Cult 37:257-269

Zhang FL, Takahata Y, Xu JB (1998) Medium and genotype factors influencing shoot regeneration from cotyledonary explants of Chinese cabbage (Brassica campestris L. ssp. Pekinensis). Plant Cell Rep 17:780-786

(Received April 16, 2009; Accepted April 28, 2009) 